\section{Atitudes relacionadas ao consentimento para doação de órgãos e tecidos para pesquisa no Brasil}

Attitudes related to consent for organ and tissue donation for research in Brazil

\author{
Carolina Stopinski Padoan ${ }^{1}$ \\ Pedro Vieira da Silva Magalhães ${ }^{1}$ \\ ${ }^{1}$ Instituto Nacional de Ciência e Tecnologia \\ Translacional em Medicina (INCT-TM), \\ Hospital de Clínicas de Porto Alegre. \\ carolpadoan@hotmail.com
}

Prezado Editor,

Há pelo menos 80 anos, tecidos e órgãos humanos são armazenados e utilizados para fins terapêuticos, educacionais, forenses e científicos ${ }^{1}$. Tais acervos de material biológico, ou biobancos, permitem importantes abordagens para a investigação de doenças, como a identificação de biomarcadores ou alvos terapêuticos futuros. O avanço na compreensão de determinadas características do tecido - anatomopatológicas, biológicas e bioquímicas - deve gerar conhecimento para promover tratamentos mais eficazes.

Vários fatores têm se mostrado capazes de influenciar a disposição de indivíduos na doação de órgãos para pesquisa em estudos internacionais. Entre eles, estão o tecido solicitado, a instituição responsável, a doença em estudo, doações em vida ou post-mortem, e, proeminentemente, questões relacionadas ao contexto sociocultural. Estes incluem benefícios dos avanços da prática médica envolvendo a comunidade, o sistema público de saúde e a qualidade de vida $^{1,2}$. Valorizar estes dados proporciona a elaboração de estratégias mais responsáveis, éticas e aceitáveis aos doadores, indo além da simples obtenção do consentimento informado ${ }^{3}$.

A disponibilidade de dados locais é indispensável para este objetivo. Muito embora seja tranquilizante saber que na Escócia e Escandinávia a visão em relação à doação é favorável ${ }^{2,3}$, não há nenhum motivo a priori para supor que o mesmo seja verdadeiro para o Brasil. A relação com o sistema público de saúde, o papel que as instituições de pesquisa possuem na comunidade e o conhecimento do benefício de pesquisas médicas para a população podem variar tanto globalmente, como em cada região. Todos esses fatores influenciam a opção de doar. Saber como o brasileiro percebe a prática de doação para pesquisa é fundamental para o impacto de um pedido de consentimento para participar de tais projetos.

Para tanto, realizamos uma busca sistemática nas bases de dados relevantes (Scopus, Medline, Lilacs, Web of Science) com as palavras-chave "biobancos", "órgão", "tecido", "pesquisa" "Brasil", "atitude", "conhecimento", em português e inglês. Dos 55 artigos localizados, 25 investigavam o conhecimento da população sobre doação para transplante e 12 abordavam aspectos éticos, técnicos e epidemiológicos dos transplantes. Não fomos capazes de localizar estudos que abordassem atitudes, opiniões ou conhecimento que o brasileiro pudesse ter sobre doação de tecidos e órgãos para pesquisa ${ }^{4}$.

Considerando doação para transplante, a marca de 10 doações por milhão de habitantes foi atingida pela primeira vez em nossa história em 20115. Mesmo assim, a desinformação é a principal barreira na captação de doadores ${ }^{6,7}$. Ainda que cerca de $80 \%$ da opinião pública relacionada à doação para transplante no Brasil seja favorável, pesquisas mencionam que a desconfiança na captação e distribuição de órgãos seguem sendo motivos para repensar a opção de doar ${ }^{8}$.

Se há dados, ainda que escassos, quanto a percepções sobre doação para transplante, eles não necessariamente informam sobre doação para pesquisa ${ }^{7}$. A recomendação do NHS britânico, de mais de uma década atrás ${ }^{9}$, sobre a necessidade de estudos originais a respeito de fatores que influenciam a doação parece ser especialmente relevante para o Brasil.

Questões relacionadas à ética da pesquisa com órgãos e tecidos no Brasil foram recentemente normatizadas pelo Ministério da Saúde e Conselho Nacional de Saúde ${ }^{10,11}$. Como resultado da falta de estudos sobre a opinião do brasileiro, a legislação cobre aspectos técnicos e direitos individuais e coletivos dos sujeitos de pesquisa realizadas por consenso baseado em princípios bioéticos ${ }^{4}$. Embora existam bons exemplos de estudos internacionais, sabe-se que características socioculturais de cada local influenciam tanto na posição do indivíduo frente a esta prática, quanto no seu consentimento em doar.

Para que os órgãos reguladores possam legislar sobre a melhor forma de abordar os indivíduos para pesquisa e obter consentimento, é fundamental saber como se sentem e o que 
pensam as pessoas acessadas para tal empreendimento. Isso permite priorizar o bem-estar dos sujeitos envolvidos e diminuir riscos e desconfortos. O desenvolvimento de estudos sobre atitudes, opiniões e aspectos psicológicos de potenciais doadores de órgãos e tecidos para pesquisa é fundamental para o avanço desta prática no Brasil.

\section{Referências}

1. Hoeyer K. The Ethics of Research Biobanking: A critical Review of the Literature. Biotechnol Genet Eng Rev 2008; 25:429-452.

2. Millar T, Walker R, Arango J-C, Ironside JW, Harrison DJ, MacIntyre DJ, Blackwood D, Smith C, Bell JE. Tissue and organ donation for research in forensic pathology: the MRC Sudden Death Brain Tissue Bank. J Pathol 2007; 213(4):369-375.

3. Hoeyer K, Olofsson B-O, Mjörndal T, Lynöe N. Informed consente and biobanks: a populationbased study of atitudes towards tissue donation for genetic research. Scand J Public Health 2004; 32(3):224-229.

4. Marodin G, França P, Rocha JCC, Campos AH. Biobanking for health research in Brazil: presente challenges and future directions. Rev Panam Salud Publica 2012; 31(6):523-528.

5. Rabelo C. Número de transplantes mais que dobra em dez anos. Agência Saúde 2012 Fev. [página na Internet] [acessado 2012 nov 3]. Disponível em: http://portalsaude.saude.gov.br/portalsaude/noticia/4234/162/numero-de-transplantes-mais-quedobra-em-dez-anos.html

6. Galvao FHF, Caires RA, Azevedo-Neto RS, Mory EK, Figueira ERR, Otsuzi TS, Bacchella T, Machado MCC. Conhecimento e opinião de estudantes de medicina sobre doação e transplante de órgãos. Rev Assoc Med Bras [periódico na Internet] 2007 Set-Out [acessado 2012 nov 3]; 53 (5) [cerca de 5p.]. Disponível em: http://www.scielo.br/scielo.php?pid=S0104 $-42302007000500015 \&$ script $=$ sci_arttext

7. Duarte PS, Pericoco S, Miyasaki MC, Ramalho HJ Abbud-Filho M. Brazilian attitudes towards organ donation and transplantation. Transplant Proc 2002; 34(2):458-459.

8. Coelho JCU, Cilião C, Parolin MB, Teixeira de Freitas AC, Gama Filho OP, Saad DT, Pistori RP, Martone D. Opinião e conhecimento da população da cidade de curitiba sobre doação e transplante de órgãos. Rev Assoc Med Bras 2007; 53(5):421-425.

9. Womack C, Jack AL. Family attitudes to research using samples taken at coroner's postmortem examinations: review of records. BMJ 2003; 327(7418): 781-782.

10. Brasil. Portaria no 2.201 de 14 de setembro de 2011. Estabelece as Diretrizes Nacionais para Biorrepositório e Biobanco de Material Biológico Humano com Finalidade de Pesquisa. Diário Oficial da União 2011; 15 set.

11. Brasil. Resolução do CNS no 441 de 12 de maio de 2011. Diário Oficial da União 2011; 18 jul. 